\title{
Calling out the COVID blues- how much of a psychological impact does the COVID-19 pandemic have on health care professionals in India
}

\author{
Arghya Halder ${ }^{1}$, Ambarish Ghosh², Nikhiles Mondal ${ }^{3}$, Birva Desai ${ }^{4}$, Priyanka Das ${ }^{5}$, \\ Satyabrata Maity ${ }^{6}$ \\ ${ }^{1}$ Assistant Professor, Institute of Psychiatry-A Centre of Excellence, IPGMER \& SSKM Hospital, Kolkata, India, \\ ${ }^{2}$ Assistant Professor and Head, ${ }^{4}$ Senior Resident, ${ }^{5}$ Clinical Psychologist, ${ }^{6} \mathrm{Junior}$ Resident, Department of Psychiatry, \\ Jagannath Gupta Institute of Medical Sciences and Hospital, Kolkata, India, ${ }^{3}$ Associate Professor, Department of \\ Psychiatry, Coochbehar Government Medical College and Hospital, West Bengal, India
}

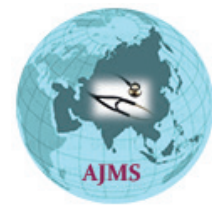

\section{A B S TR A T T}

Background: COVID-19 pandemic is one of the rarest health crises the world has ever encountered. As mental health professionals; we need to consider the psychological impact of the pandemic. There are certain groups of people that are largely more vulnerable to pernicious effects on mental health including frontline healthcare workers. Hence, the current study was undertaken look into the minds of our covid warriors. Aims and Objectives: This study aims to assess psychological impact of COVID-19 pandemic among health care professionals, with the primary objectives being to study: 1 . Perceived stress regarding COVID-19 pandemic among health care professionals. 2. Stigma associated with the pandemic, faced by health care professionals in their surroundings as well as in the society. 3. Obsessive-Compulsive symptoms among the health care professionals. The secondary objective of the study is to compare between High and Low exposure groups on the basis of different variables.Materials and Methods: This study is an observational, cross-sectional study wherein the sample size is 410 , taken by consequent sampling. Data was collected from health care professionals all over India, by manual or digital interview. Health care professionals of a tertiary care hospital were taken up for the study including doctors, nurses and other hospital staff. Results: On K10 scale, 369 (90\%) of the subjects had scores below 25, meaning they reported to have no or mild perceived stress, whereas 41 of them $(10 \%)$ had scores 25 or above, meaning to have moderate or severe perceived stress. Forty $(9.8 \%)$ subjects reported to be experiencing panic symptoms at the time of the interview. One hundred twenty-eight (31.2\%) admitted to have faced stigma from the society in at least one of the facets of the questionnaire based on SARI stigma scale. 39 people $(9.5 \%)$ reported to be experiencing OC symptoms at the time of interview. Conclusion: With this research we conclude that owing to the ongoing COVID-19 pandemic, the health care professionals are under a lot of stress, many of them have also experienced panic like symptoms. Large scale screenings should be carried out at regular intervals at hospitals to keep a check on the mental health of health care workers. Mental health should be given a priority by the government officials and sufficient awareness campaigns should be rolled out.

Key words: COVID-19; Stress; Stigma; Panic; Health care professionals

\section{Access this article online}

\section{Website:}

http://nepjol.info/index.php/AJMS DOI: 10.3126/ajms.v12i5.33324 E-ISSN: 2091-0576 P-ISSN: 2467-9100

Copyright (c) 2021 Asian Journal of Medical Sciences

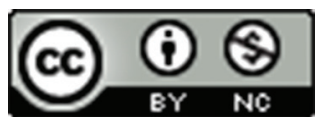

This work is licensed under a Creative Commons Attribution-NonCommercial 4.0 International License.

\section{INTRODUCTION}

Come 2020, and the world has been torpefied under the global crisis due to the COVID-19 pandemic. The extent and severity have been such that the word 2020 itself brings about a phobic chill down the spine. As we write, there are already more than 58 million cases worldwide with over 1.4 million deaths. ${ }^{1}$ India till now has reported over 9 million cases and 1.3 lac deaths. ${ }^{1}$ The subsequent lockdowns imposed worldwide along with its unexpected

Address for Correspondence:

Dr. Birva Desai, Senior Resident, Department of Psychiatry, Jagannath Gupta Institute of Medical Sciences and Hospital, Kolkata, India.

Mobile: +91-9879861751. E-mail: drbirvadesai21@gmail.com 
direct and indirect consequences have been unparallel, including India's total lockdown of 1.3 billion people lasting for over 40 days. Though not reported, panophobia and chronophobia seem to be spectacularly rising. ${ }^{2}$ Unarguably, this is one of the rarest health crises the world has ever encountered.

As mental health professionals, we cannot trivialize the account of zeroing in on the mental health impact of a pandemic of these proportions. Previous studies regarding effects on mental health of outbreaks of SARS, MERS, Ebola, etc. give an equitable insight into the enormity of the problem. ${ }^{3}$ Major health institutions and organizations like Oxford University, World Psychiatric Association, National Health Survey UK, Royal College of Psychiatry, London, etc. have called for urgent researches into the mental health impact of this pandemic. ${ }^{4}$ As we write this, a number of studies evaluating the mental health impact of COVID-19 pandemic are surfacing.

There are certain groups of people that are largely more vulnerable to pernicious effects on mental health. This includes frontline healthcare workers such as doctors, nurses, hospital management personnel and housekeeping staff; people with comorbidities, the elderly, those with existing mental illnesses and migrants among others. ${ }^{5}$

Health care professionals are particularly at higher risk of facing the impact on their mental health due to several reasons. ${ }^{6}$ There is a disparity between their needs and the provisions they are availed with. They face direct risk of infection, long working hours, shortages of PPE and rapid testing kits during the initial months, loneliness, physical fatigue, burnout and separation from families.

In India, in addition to these, health care workers, face additional challenges such as stigma from people in the community and their neighborhood. Unfortunately, there have been incidences where in people working in hospitals have been thrown out of their residences for fears of being infected with the virus, as well as incidences of violence inflicted on the health care professionals due to death of a near one or due to their screening activities in containment zones. They also face other challenges such as providing aid and support to families, meeting the family demands, concerns about getting the virus to their families, uncertainty about their own careers, uncertainty about support from hospital management and lack of access to up-to-date information or a wide array of constantly changing guidelines from reliable sources. They get overburdened if their colleagues test positive for the virus and have to get isolated. The pain of letting go of people with other illnesses due to overwhelming numbers of Covid patients and to watch them suffer is excruciating for any health care worker. Moreover, hospital management staff is baffled with economic stresses if entire departments or the hospital itself has to be shut due to large number of their staff contacting the virus. There have also been events of suicides committed by young health care workers posted for duties in Covid hospitals. Needless to say, such circumstances can be a trigger to lasting mind injuries like depression, anxiety, stress, suicidality, panic and more. ${ }^{7}$

Hence, there is a dire need to look into the minds of our Covid warriors, to call out their blues and thus do our bit to help them overcome it. This study aims at finding out what are the mental health issues faced by health care professionals owing to the COVID-19 pandemic.

\section{AIMS AND OBJECTIVES}

This study aims to assess psychological impact of COVID-19 pandemic among health care professionals, with the primary objectives being:

1. To study perceived stress regarding COVID-19 pandemic among health care professionals

2. To study the stigma associated with the pandemic, faced by health care professionals in their surroundings as well as in the society

3. To assess for Obsessive-Compulsive symptoms among the health care professionals.

The secondary objective of the study was to compare between High and Low exposure groups (e.g.-High Exposure Group consists of Health care professionals working in ER, ICU, Fever clinic, General Medicine OPD, Respiratory Medicine OPD, ENT OPD, Eye OPD, COVID ward, Isolation ward or exposed to COVID patient or suspected COVID patient etc.) on the basis of different variables.

\section{MATERIALS AND METHODS}

This study is an observational, cross-sectional study wherein the sample size is 410. Data was collected from health care professionals all over the country working in a tertiary care centre by digital or manual interview. For digital interview, the design was made such that the interview form could be submitted only after the consent was obtained digitally. For manual interview, consent was taken in written. As mental health professionals, the researchers would be available to assist those whose mental health seemed to be compromised during the interview, however, that would be done after the interview. For digital interview, contact details of the researchers were provided if any participant required to contact them. The questionnaires were self-administered and structured; however, for 
both the interviews, the researchers were available if the participants had any queries. Other data that was collected includes: age, sex, education, occupational departments, marital status, history of any medical comorbidities, past or family history of psychiatric illness and OCD (ObsessiveCompulsive Disorder), whether the participant experienced any panic like symptoms (panic symptoms were explained in the interview itself), substance history, whether or not the substance consumption increased during the pandemic and lockdown, whether or not they were working in a high risk setup such as fever clinics, COVID wards or ICU, etc., whether or not they had come in direct contact with a COVID positive patient or suspect. The study was preapproved by the ethical committee of the Institution with Ethical Approval No: JIMSH-IEC-02-2020.

The data obtained was analysed manually as well as using SPSS software. Health care professionals, aged 18 or more, of a tertiary care hospital were taken up for the study including doctors (clinical and non-clinical), nurses and other hospital staff such as paramedical, housekeeping \& administrative staff. Health care professionals not willing to give consent for the study, those below the age of 18 , or those not working in a tertiary care centre were excluded.

Following are the study tools used for this study:

1. Semi structured proforma for socio-demographic and clinical variables

2. Kessler Psychological Distress Scale (K10) ${ }^{8}$

3. Questionnaire enquiring for stigma faced from the society - based on SARI stigma scale ${ }^{9}$

4. Yale-Brown Obsessive-Compulsive Scale ${ }^{10}$

\section{RESULTS}

This study was conducted with 410 health care professionals all over India, by manual or digital interview. Health care professionals were grouped into five categories- doctors in clinical specialties, doctors in non-clinical specialties, nurses, other hospital staff at high risk and other hospital staff at low risk. The risk for other hospital staff was decided based on whether they come in direct contact with COVID-19 patients or not during their routine work. Out of the 410 subjects, $325(79.1 \%)$ were clinical doctors, $20(4.9 \%)$ were non-clinical doctors, 21 (5.1\%) were nurses, 36 (8.8\%) were other hospital staffs at high risk and $8(1.9 \%)$ were other hospital staffs at low risk (Table 1).

Of the 410 subjects, $148(36.1 \%)$ were females and 262 $(63.9 \%)$ were males. They were also grouped into two categories as per their age, which are those below the age of 50 years and those 50 years and above. 274 were below the age of $50(66.8 \%)$ and 136 were 50 and above (33.2\%).
337 subjects were married $(82.2 \%)$ and 73 were unmarried $(17.8 \%)$ (Table 2).

One hundred three subjects (25.1\%) out of 410 gave history of comorbidities such as diabetes, hypertension, COPD or asthma. Twenty-one people had a previous history of some mental illness (5.1\%) of which 12 gave a prior history of having OCD $(2.9 \%) .39$ people $(9.5 \%)$ reported to be experiencing OC symptoms at the time of interview on the Yale Brown Obsessive Compulsive Scale Symptoms Checklist. 40 people $(9.8 \%)$ had a family history of mental illness, while $21(5.1 \%)$ were unsure for the same. Forty people $(9.8 \%)$ had a previous history of substance use, whereas 30 people $(7.3 \%)$ reported that either their substance use had increased or they had started consuming substances during the lockdown (Table 3).

Of the 410 subjects, $169(41.2 \%)$ reported to be working in a high-risk setup such as fever clinics, COVID wards, ICU or operation theatres, while 112 people $(27.3 \%)$ reported to have come in direct contact with a COVID positive case or a suspect (Table 4).

On Kessler Psychological Distress Scale (K10), 369 $(90 \%)$ of the subjects had scores below 25 , meaning they

\begin{tabular}{lc} 
Table 1: Sample size as per categories \\
\hline Categories & $\begin{array}{c}\text { Number (Percentage) } \\
\text { Total }=\mathbf{4 1 0}\end{array}$ \\
\hline Clinical doctors & $325(79.1 \%)$ \\
Non-clinical doctors & $20(4.9 \%)$ \\
Nurses & $21(5.1 \%)$ \\
Other hospital staffs at high risk & $36(8.8 \%)$ \\
Other hospital staffs at low risk & $8(1.9 \%)$ \\
\hline
\end{tabular}

\begin{tabular}{|c|c|c|}
\hline Variables & & TOTAL $=410 \mathrm{~N}(\%)$ \\
\hline Gender & Male & $\begin{array}{l}262(63.9) \\
148(36.1)\end{array}$ \\
\hline Age & $\begin{array}{l}\text { Below } 50 \text { yrs } \\
\geq 50 \text { yrs }\end{array}$ & $\begin{array}{l}274(66.8) \\
136(33.2)\end{array}$ \\
\hline Marital status & $\begin{array}{l}\text { Married } \\
\text { Unmarried }\end{array}$ & $\begin{array}{c}337(82.2) \\
73(17.8)\end{array}$ \\
\hline
\end{tabular}

Table 3: Distribution of sample as per past and family histories

\begin{tabular}{lc}
\hline Variables & N (\%) \\
\hline Subjects with physical co-morbidities & $103(25.1)$ \\
History of mental illness & $21(5.1)$ \\
History of OCD & $12(2.9)$ \\
Family history of mental illness & $40(9.8)$ \\
Subjects experiences OC symptoms during interview & $39(9.5)$ \\
History of substance use & $40(9.8)$ \\
Substance use increased or started during & $30(7.3)$ \\
lockdown &
\end{tabular}


reported to have no or mild perceived stress, whereas 41 of them $(10 \%)$ had scores 25 or above, meaning to have moderate or severe perceived stress (Chart 1). The p-value was 0.008 for age and K-10 scores, which means that it is statistically significant. Those with age less than 50 perceived more stress than the elder population. The $\mathrm{p}$-value for various specialties and K-10 scores was 0.033 which is statistically significant. Proportionately nurses perceived more stress than other categories, followed by clinical doctors. $9 \%$ of married people and $16 \%$ of unmarried people perceived moderate to severe stress, with the $\mathrm{p}$-value being 0.043 ; which means unmarried people perceived more stress (moderate to severe) as compared to married ones. Among them 15\% have been perceiving moderate to severe stress had a history of mental illness whereas the rest $85 \%$ did not have, p-value being 0.004 which is statistically significant. Around $76 \%$ of those perceiving moderate to severe stress had no history of substance use. $(\mathrm{p}=0.001)$. Out of the 41 people perceiving moderate to severe stress, around 61\% were working in a high-risk setup such as fever clinics, COVID wards, ICU or operation theatres, which is significant $(\mathrm{p}<0.05)$. Conversely, only $22 \%$ of those perceiving moderate to severe stress had come in direct contact with a COVID

\begin{tabular}{lc} 
Table 4: No.of people working in high-risk \\
setups and having come in contact with COVID \\
suspects or patients \\
\hline Variables & $\mathbf{n}(\%)$ \\
\hline $\begin{array}{l}\text { Subjects working in high-risk set-up } \\
\text { Subjects with direct contact with Covid/suspected } \\
\text { patients }\end{array}$ & $169(41.2)$ \\
\hline
\end{tabular}

positive case or a suspect. ( $p>0.05)$. Factors such as sex of the individual, history of OCD in the past, physical comorbidities, family history of mental illness, having come in direct contact with a COVID positive case or a suspect, did not have a statistically significant impact on K-10 scores ( $\mathrm{p}>0.05)$ (Table 5).

A total of $40(9.8 \%)$ subjects reported to be experiencing panic symptoms at the time of the interview. Of them 33 belonged to age group of less than 50 . The p-value for age was 0.02 which is statistically significant. $87.5 \%$ of those experiencing panic symptoms had no prior history of mental illness $(p=0.02)$. Factors such as sex of the individual, which specialty they belonged to, marital status, prior history of OCD, physical comorbidities, family history of mental illness, having come in direct contact with a COVID positive case or a suspect, did not have a statistically significant impact on whether the person experienced panic symptoms. (p,>0.05) (Table 6).

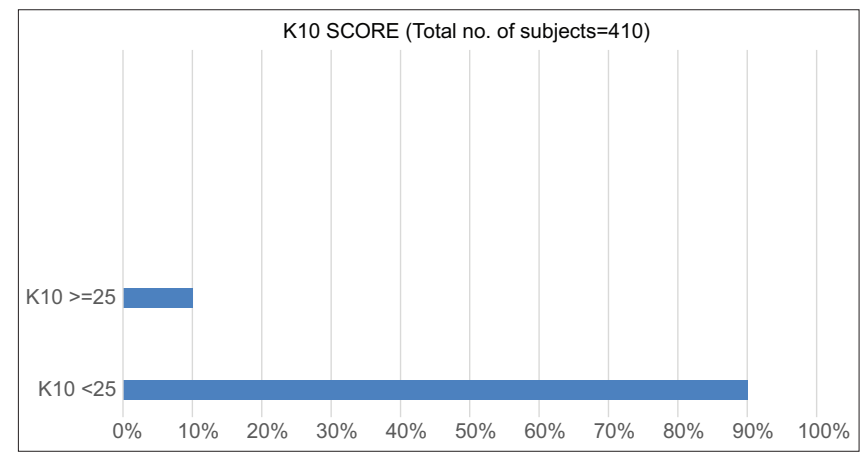

Chart 1: K10 Score (Total no. of subjects=410) Table 5: K-10 Scores with different variables

\begin{tabular}{|c|c|c|c|c|}
\hline Variables & & K10 score <25 & K10 score $\geq 25$ & $\mathbf{P}$ \\
\hline \multirow[t]{2}{*}{ Age } & $<50$ yrs & $239(58.29 \%)$ & $35(8.54 \%)$ & 0.008 \\
\hline & $\geq 50 \mathrm{yrs}$ & $130(31.71 \%)$ & $6(1.46 \%)$ & \\
\hline \multirow[t]{2}{*}{ Sex } & Female & $135(32.93 \%)$ & $13(3.17 \%)$ & 0.537 \\
\hline & Male & $234(57.07 \%)$ & $28(6.83 \%)$ & \\
\hline \multirow[t]{5}{*}{ Groups } & Clinical doctors & $294(71.71 \%)$ & $31(7.56 \%)$ & 0.033 \\
\hline & Non-clinical doctors & $16(3.9 \%)$ & $4(0.98 \%)$ & \\
\hline & Nurses & $20(4.88 \%)$ & $1(0.24 \%)$ & \\
\hline & Hospital staffs at high risk & $34(8.29 \%)$ & $2(0.49 \%)$ & \\
\hline & Hospital staffs at low risk & $5(1.22 \%)$ & $3(0.73 \%)$ & \\
\hline \multirow[t]{2}{*}{ Marital status } & Married & $308(75.12 \%)$ & $29(7.07 \%)$ & 0.043 \\
\hline & Unmarried & $61(14.88 \%)$ & $12(2.93 \%)$ & \\
\hline \multirow[t]{2}{*}{$\mathrm{H} / \mathrm{O}$ Mental illness } & Present & $15(3.66 \%)$ & $6(1.46 \%)$ & 0.004 \\
\hline & Absent & $354(86.34 \%)$ & $35(8.54 \%)$ & \\
\hline \multirow[t]{2}{*}{$\mathrm{H} / \mathrm{O} O \mathrm{OCD}$} & Present & $9(2.2 \%)$ & $3(0.73 \%)$ & 0.709 \\
\hline & Absent & $360(87.8 \%)$ & $38(9.27 \%)$ & \\
\hline \multirow[t]{3}{*}{ Family h/o mental illness } & Present & $34(8.29 \%)$ & $6(1.46 \%)$ & 0.540 \\
\hline & Absent & $316(77.07 \%)$ & $33(8.05 \%)$ & \\
\hline & Unsure & $19(4.63 \%)$ & $2(0.49 \%)$ & \\
\hline \multirow[t]{2}{*}{ History of substance use } & Present & $30(7.32 \%)$ & $10(2.44 \%)$ & 0.001 \\
\hline & Absent & $339(82.68 \%)$ & $31(7.56 \%)$ & \\
\hline \multirow[t]{2}{*}{ Substance use increased / started during pandemic } & Yes & $24(5.85 \%)$ & $6(1.46 \%)$ & 0.058 \\
\hline & No & $345(84.15 \%)$ & $35(8.54 \%)$ & \\
\hline
\end{tabular}


Of the study subjects, $128(31.2 \%)$ admitted to have faced stigma from the society in at least one of the facets of the questionnaire based on SARI stigma scale (Chart 2). Majority of those who faced stigma in some or the other way were below the age of 50 , and this difference is statistically significant. $(\mathrm{p}<0.05)$. More proportion of other medical staff was found to have faced stigma than doctors and nurses. Among doctors, those in clinical branches reported to have faced more stigma than the non-clinical ones; and these differences were statistically significant. (p value 0.012 ). Of the 128 facing stigma, around $26 \%$ were unmarried and $74 \%$ were married; p-value being 0.0004 which is significant. Majority of those facing stigma had no history of mental illness with p-value being less than $0.005 .80 \%$ of those with family history of mental denied having faced stigma, whereas $11 \%$ reported to have faced stigma; the rest being unsure of the family history. $(\mathrm{p}=0.024)$. Around $84 \%$ of those facing stigma had no history of substance use. $(p=0.002)$. Around $45 \%$ of those facing stigma were working in a high-risk setup such as fever clinics, COVID wards, ICU or operation theatres; whereas
$37 \%$ had come in direct contact with a COVID positive case or a suspect. Factors such as sex of the individual, history of OCD in the past, physical comorbidities, increase or decrease in the substance use did not have a statistically significant impact on stigma outcomes. ( $p>0.05$ ) (Table 7).

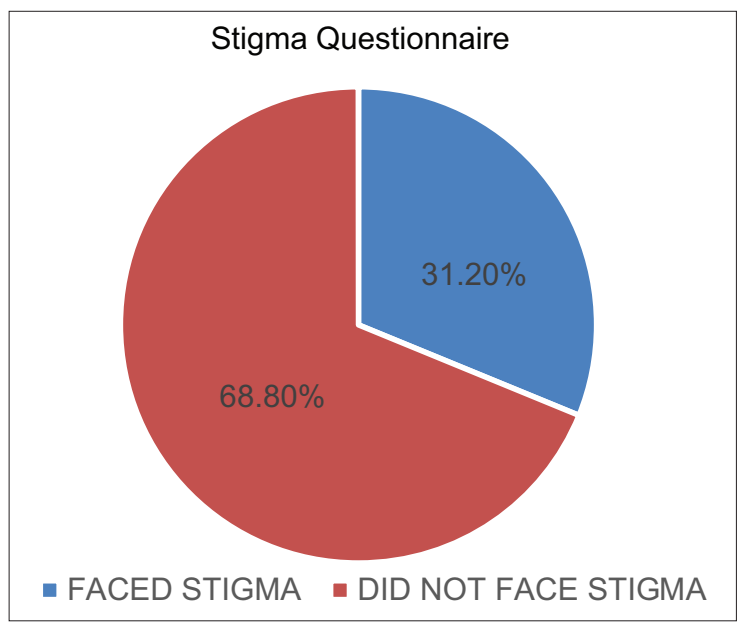

Chart 2 : Stigma Questionnaire

\section{Table 6: Panic outcomes with different variables}

\begin{tabular}{|c|c|c|c|c|}
\hline Variables & & Experienced panic symptoms & Did not experience panic symptoms & $\mathbf{P}$ \\
\hline \multirow[t]{2}{*}{ Age } & $<50$ yrs & $33(8.05 \%)$ & $241(58.78 \%)$ & 0.027 \\
\hline & $\geq 50 \mathrm{yrs}$ & $7(1.71 \%)$ & $129(31.46 \%)$ & \\
\hline \multirow[t]{2}{*}{ Sex } & Female & $20(4.88 \%)$ & $128(31.22 \%)$ & 0.054 \\
\hline & Male & $20(4.88 \%)$ & $242(59.02 \%)$ & \\
\hline \multirow[t]{5}{*}{ Groups } & Clinical doctors & $30(7.32 \%)$ & $295(71.95 \%)$ & 0.759 \\
\hline & Non-clinical doctors & $1(0.24 \%)$ & $19(4.63 \%)$ & \\
\hline & Nurses & $3(0.73 \%)$ & $18(4.39 \%)$ & \\
\hline & Hospital staffs at high risk & $5(1.22 \%)$ & $31(7.56 \%)$ & \\
\hline & Hospital staffs at low risk & $1(0.24 \%)$ & $7(1.71 \%)$ & \\
\hline \multirow[t]{2}{*}{$\mathrm{H} / \mathrm{O}$ Mental illness } & Present & $5(1.22 \%)$ & $16(3.9 \%)$ & 0.026 \\
\hline & Absent & $35(8.54 \%)$ & $354(86.34 \%)$ & \\
\hline
\end{tabular}

\begin{tabular}{|c|c|c|c|c|}
\hline Variables & & Faced stigma & Did not face stigma & $p$ \\
\hline \multirow[t]{2}{*}{ Age } & $<50$ yrs & $109(26.59 \%)$ & $165(40.24 \%)$ & 0.05 \\
\hline & $\geq 50$ yrs & $19(4.63 \%)$ & $117(28.54 \%)$ & \\
\hline \multirow[t]{2}{*}{ Sex } & Female & $46(11.22 \%)$ & $102(24.88 \%)$ & 0.954 \\
\hline & Male & $82(20 \%)$ & $180(43.9 \%)$ & \\
\hline \multirow[t]{5}{*}{ Groups } & Clinical doctors & $93(22.68 \%)$ & $232(56.59 \%)$ & 0.012 \\
\hline & Non-clinical doctors & $5(1.22 \%)$ & $15(3.66 \%)$ & \\
\hline & Nurses & $6(1.46 \%)$ & $15(3.66 \%)$ & \\
\hline & Hospital staffs at high risk & $19(4.63 \%)$ & $17(4.15 \%)$ & \\
\hline & Hospital staffs at low risk & $5(1.22 \%)$ & $3(0.73 \%)$ & \\
\hline \multirow[t]{2}{*}{ Marital status } & Married & $95(23.17 \%)$ & $242(59.02 \%)$ & 0.0004 \\
\hline & Unmarried & $33(8.05 \%)$ & $40(9.76 \%)$ & \\
\hline \multirow[t]{2}{*}{ H/O Mental illness } & Present & $14(3.41 \%)$ & $7(1.71 \%)$ & $<0.005$ \\
\hline & Absent & $114(27.8 \%)$ & $275(67.07 \%)$ & \\
\hline \multirow[t]{3}{*}{ Family H/O Mental illness } & Present & $14(3.41 \%)$ & $26(6.34 \%)$ & 0.024 \\
\hline & Absent & $102(24.88 \%)$ & $247(60.24 \%)$ & \\
\hline & Unsure & $12(2.93 \%)$ & $9(2.2 \%)$ & \\
\hline \multirow{2}{*}{ History of substance use } & Present & $21(5.12 \%)$ & $19(4.63 \%)$ & 0.002 \\
\hline & Absent & $107(26.1 \%)$ & $263(64.15 \%)$ & \\
\hline \multirow[t]{2}{*}{ Substance use increased / started during pandemic } & Yes & $18(4.39 \%)$ & $12(2.93 \%)$ & $<0.05$ \\
\hline & No & $110(26.83 \%)$ & $270(65.85 \%)$ & \\
\hline
\end{tabular}




\section{DISCUSSION}

This study was conducted with 410 health care professionals all over India, by manual or digital interview. The sample consisted of more males than females, and more people below the age of 50 , which is in accordance with the demographic data of India. It was found that around 9.8\% people had a previous history of substance use whereas $7.3 \%$ reported to have started substance use or increased it during the pandemic and lockdown. It is a well-known fact that people who use substances often blame it to their stressful circumstances; the current pandemic and subsequent lockdown which stopped almost all businesses has been a major stressor in the lives of majority of the people around.

Of the 410 health care professionals, $90 \%$ reported to perceive no or mild stress and only 10 perceived moderate to severe stress. This means that overall healthcare professionals either do not consider the Covid-19 pandemic as a major stressor, or do not admit to be stressed out due to such outbreaks. Coming in contact with patients with various other diseases is a routine for health care workers and hence one particular disease might not be perceived as a major stressor. Another probable explanation could be the fact that health care workers also often face burnouts and also many other stressful life events in day to day lives; which enhances their coping abilities. However, an important finding of this study that cannot be less highlighted is that $10 \%$ of the people did admit to have perceived moderate to severe stress. Many reasons could be cited for this: long duty hours, fatigue, burnout, constant fear of contacting the virus, bringing the virus home, large number of case fatalities, peers contacting the virus or losing lives to it, fear of being ostracized, a constant uncertainty regarding the future and many more.

Interestingly, it was found that younger population perceived more stress than the elderly, that is, those more than 50 years of age. Possibly this could be because of the fact that in India, since the pandemic began, those above 50-60 years of age were advised to stay at home and were also exempted from their duties, even the health care professionals. The younger professionals continued their duties and often also had to make up for the absence of senior citizens; which increased their chances of being exposed to the virus in concern. Conversely, it could also simply mean that age and experience improve coping abilities! Similar results were found with unmarried people, who perceived more stress than the married ones.

Of the various specialties, nurses were found to perceive maximum stress. Same goes with those working in high-risk setups as explained earlier. This is understandable owing to the fact that nurses and those working in high-risk setups in general come more in contact with patients. Also, in such pandemic situations more often than not they are overworked, fatigued, burnt out, worried about bringing the virus home and more. Those with prior history of mental illnesses perceived more stress in this study. Mental illness is itself a stressor, and such circumstances such as nationwide lockdown make a person with mental illness worry more about various factors such as accessibility to health care, medications, worsening of symptoms, adjustment to virtual medical consultations, etc. Coming in direct contact with a COVID positive patient or suspect did not seem to impact the perceived stress levels, like other factors mentioned earlier.

Not many factors seemed to impact the subjects in terms of experiencing panic like symptoms, except for age and previous history of mental illness. Younger persons less than 50 years of age experienced panic symptoms more than the elder counterpart. Since they were also found to perceive more stress, that might have led to experiencing more panic. One interesting finding was that vast majority of those who had NO history of previous mental illnesses experienced more panic than those with history of mental illnesses. One probable explanation, amongst many, behind this is that those with mental illnesses might have experienced panic like symptoms at some point of time in life, and they might attribute it to their mental illness.

Almost a third of the study population reported to have faced stigma in some or the other way, which is a very striking finding. Again, younger people reported to have face more stigma than the elderly. A novel way of looking at the overall results of the younger population of this study could be that they report their experiences more easily and more vigilant about the same. However, this is just an observation and no studies are available to support this. Other medical staff reported to have faced more stigma than doctors and nurses. Probably, education levels and coping abilities might have played a major role here. Doctors from clinical branches felt more stigmatized than doctors from para clinical branches. This is understandable because the former are more exposed to the virus than the others. Majority of those with previous or family history of mental illness denied facing any stigma. This might be due to the fact that history of mental illness might have made them already experience stigma in some or the other way. The important finding was that $45 \%$ and $37 \%$ of those working in high-risk setups and in direct contact with a COVID case or suspect respectively faced stigma. This is indicative of a lot of things. COVID-19 has become a disease which has caused widespread social discrimination. It could be either to the fear of the virus or the widespread flawed perception of the society as a whole. Such high 
prevalence of stigma talks more about the society than the affected individuals.

The results of our study are similar to those of other similar studies conducted in Phillipines, China, Italy and Spain. ${ }^{11-15}$

\section{CONCLUSION}

As the name goes, this study was intended to call out the blues encountered due to the covid-19 pandemic; especially by the frontline warriors, that is the health care professionals in India. With this research we conclude that owing to the ongoing COVID-19 pandemic, the health care professionals are under a lot of stress, many of them have also experienced panic like symptoms. Of special mention is the mental health of the younger generation working in high risk setups, be it doctors nurses or paramedical staff. And as a negative feedback loop, they are also facing the humongous challenge of being stigmatized by the society. For a pandemic of such proportions, mental health of health care professionals should be considered as a serious matter requiring combined efforts by the hospitals, the government and the community.

\section{RECOMMENDATIONS}

We wish to recommend a few points in this regard, more specifically for the Indian scenario. Large scale screenings should be carried out at regular intervals at hospitals to keep a check on the mental health of the soldiers clad in white. Mental health professionals can help in this mammoth task by setting up special clinics for the hospital staff. Programmes such as psychological first aid, trauma risk management, screening for post-traumatic stress disorder, post covid/quarantine rehabilitation should be arranged and maintained.

Toll-free helpline numbers can be set up for those who need to talk and seek help. Teleconsultations should be encouraged if there is shortage of mental health professionals. Health care professionals should be made aware of their worsening mental health by their group supervisors, or those in authorities. A team is as strong as its weakest link. Hence, the motto for hospitals should be to create supportive workplaces and teams, where colleagues and peers talk to one another and leaders have a proactive role. Active monitoring, reassuring, sharing of experiences should be carried out at regular intervals to help the coping process.

The stigma outcomes obtained in this study tell us more about the society at large rather than anything else. The society needs to be less hostile and more inclusive.
Government can play a major role in creating awareness amongst the common public to reduce the stigma towards the health care professionals by generating large scale campaigns for the same. Motivating these professionals, rewarding them, appreciating them and at the least recognizing the efforts of the thousands of health care professionals tirelessly working to fight the pandemic can help them cope up with the stress of the pandemic and to adapt to this "new normal" manner of working. Mental health is important, and at such times, that of health care professionals is a priority and should be addressed accordingly.

\section{ACKNOWLEDGEMENT}

The authors take the opportunity to thank Ms Swati Patel for her help in statistical analysis.

\section{REFERENCES}

1. https://www.worldometers.info/coronavirus

2. Arora A, Jha AK, Alat $P$ and Das SS. Understanding coronaphobia. Asian J Psychiatr. 2020; 54:102384. https://doi.org/10.1016/j.ajp.2020.102384

3. Preti E, Di Mattei V, Perego G, Ferrari F, Mazzetti M, Taranto P, et al. The Psychological Impact of Epidemic and Pandemic Outbreaks on Healthcare Workers: Rapid Review of the Evidence. Curr Psychiatry Rep. 2020; 22(8):43. https://doi.org/10.1007/s11920-020-01166-z

4. Holmes EA, O'Connor RC, Perry VH, Tracey I, Wessely S, Arseneault $\mathrm{L}$, et al. Multidisciplinary research priorities for the COVID-19 pandemic: a call for action for mental health science. Lancet Psychiatry. 2020;7(6):547-560.

https://doi.org/10.1016/S2215-0366(20)30168-1

5. Blake $H$, Bermingham $F$, Johnson $G$ and Tabner A. Mitigating the Psychological Impact of COVID-19 on Healthcare Workers: A Digital Learning Package. Int J Environ Res Public Health. 2020;17(9):2997. https://doi.org/10.3390/ijerph17092997

6. Luo M, Guo L, Yu M, Jiang W and Wang H. The psychological and mental impact of coronavirus disease 2019 (COVID-19) on medical staff and general public - A systematic review and metaanalysis. Psychiatry Res. 2020; 291:113190.

https://doi.org/10.1016/j.psychres.2020.113190

7. Tirupathi R, Bharathidasan K, Palabindala V, Salim SA and AlTawfiq JA. Comprehensive review of mask utility and challenges during the COVID-19 pandemic. Infez Med. 2020;28(suppl 1):57-63.

8. Kessler RC, Andrew G, Colpe LJ, Hiripi E, Mroczek DK, Normand SLT, et al. Short screening scales to monitor population prevalences and trends in non-specific psychological distress. Psychological Medicine. 2020; 32: 959-956. https://doi.org/10.1017/S0033291702006074

9. Dadun, Peters RMH, Van Brakel WH, Lusli M, Damayanti R, Bunders JFG and Irwanto. Cultural validation of a new instrument to measure leprosy-related stigma: the SARI Stigma Scale. Leprosy Review. 2017;88(1):23-42.

https://doi.org/10.47276/lr.88.1.23 
10. Goodman WK, Price LH, Rasmussen SA, Mazure C, Delgado P, Heninger GR, et al. The Yale-Brown Obsessive Compulsive Scale. II. Validity: Arch Gen Psychiatry. 1989;46(11):1012-1016. https://doi.org/10.1001/archpsyc.1989.01810110054008

11. Tee ML, Tee CA, Anlacan JP, Aligam KJG, Reyes PWC Kuruchittham V, et al. Psychological impact of COVID-19 pandemic in the Philippines. J Affect Disord. 2020; 277:379-391. https://doi.org/10.1016/j.jad.2020.08.043

12. Que J, Shi L, Deng J, Liu J, Zhang L, Wu S, et al. Psychological impact of the COVID-19 pandemic on healthcare workers: a crosssectional study in China. Gen Psychiatr. 2020;33(3):e100259. https://doi.org/10.1136/gpsych-2020-100259

13. Maugeri G, Castrogiovanni P, Battaglia G, Pippi R,
D'Agata V, Palma A, et al. The impact of physical activity on psychological health during Covid-19 pandemic in Italy. Heliyon. 2020;6(6):e04315.

https://doi.org/10.1016/j.heliyon.2020.e04315

14. Felice C, Di Tanna GL, Zanus G and Grossi U. Impact of COVID-19 Outbreak on Healthcare Workers in Italy: Results from a National E-Survey. J Community Health. 2020;45(4):675-683. https://doi.org/10.1007/s10900-020-00845-5

15. Fernández VÁ and Bouchard JP. Covid-19 en Espagne : l'impact psychologique de la pandémie sur les infirmiers [COVID-19 in Spain: the psychological impact of the pandemic on nurses]. Rev Infirm. 2020;69(264):33-35. French. https://doi.org/10.1016/j.revinf.2020.08.007

\section{Author's contribution:}

BD-Concept and design of the study, interpreted results, prepared and critically reviewed first draft of medicine; $\mathbf{A H}$ - Analyzed and interpreted the study design prepared and edited the manuscript; AG-Statistically analyzed, reviewed the study and co-ordinated the study; PD, SM-Aided in data collection and reviewed the manuscript; NM-Mentored, guided, thoroughly reviewed and supported the entire project and manuscript.

Work attributed to:

Jagannath Gupta Institute of Medical Sciences and Hospital, Kolkata, India.

Orcid ID:

Dr. Arghya Halder- (D) https://orcid.org/0000-0002-1914-4413

Dr. Ambarish Ghosh- (i) https://orcid.org/0000-0003-4475-5125

Dr. Nikhiles Mondal- (D https://orcid.org/0000-0003-2065-272X

Dr. Birva Desai- (1) https://orcid.org/0000-0001-6323-6131

Mrs Priyanka Das- (1) https://orcid.org/0000-0003-2868-7521

Dr. Satyabrata Maity- (i) https://orcid.org/0000-0002-7218-6946

Source of Funding: None, Conflict of Interest: None 